\title{
The role of radiation therapy and particle therapy in renal cell carcinoma: current evidence and future perspectives
}

\author{
Charlien Berghen ${ }^{1}$, Maarten Albersen ${ }^{2}$, Robin De Roover ${ }^{1}$, Kato Rans ${ }^{1}$, Benoit Beuselinck ${ }^{3}$, Karel \\ Decaestecker $^{4}$, Kenneth Poels ${ }^{1}$, Francois-Xavier Otte ${ }^{5}$, Steven Joniau ${ }^{2}$, Karin Haustermans ${ }^{1}$, Gert De \\ Meerleer $^{1}$ \\ 'Department of Radiation Oncology, University Hospitals Leuven, Leuven 3000, Belgium. \\ ${ }^{2}$ Department of Urology, University Hospitals Leuven, Leuven 3000, Belgium. \\ ${ }^{3}$ Department of General Medical Oncology, University Hospitals Leuven, Leuven Cancer Institute, and Laboratory of \\ experimental Oncology, Department of Oncology, Catholic University Leuven, Leuven 3000, Belgium. \\ ${ }^{4}$ Department of Urology, Ghent University Hospital, Leuven 3000, Belgium. \\ ${ }^{5}$ Department of Radiation Oncology, Institut Jules Bordet, Brussels 1000, Belgium.
}

Correspondence to: Dr. Charlien Berghen, Department of Radiation Oncology, University Hospitals Leuven, Herestraat 49, Leuven 3000, Belgium. E-mail: charlien.berghen@uzleuven.be

How to cite this article: Berghen C, Albersen M, De Roover R, Rans K, Beuselinck B, Decaestecker K, Poels K, Otte FX, Joniau S, Haustermans K, De Meerleer $G$. The role of radiation therapy and particle therapy in renal cell carcinoma: current evidence and future perspectives. J Cancer Metastasis Treat 2021;7:58. https://dx.doi.org/10.20517/2394-4722.2021.123

Received: 25 May 2021 First Decision: 29 Jun 2021 Revised: 29 Jul 2021 Accepted: 20 Aug 2021 Published: 20 Oct 2021

Academic Editors: Lucio Miele, Boris Reva Copy Editor: Yue-Yue Zhang Production Editor: Yue-Yue Zhang

\begin{abstract}
For both primary and metastatic renal cell carcinoma (RCC), treatment with stereotactic body radiotherapy (SBRT) has found its way into clinical practice. Being a non-invasive outpatient procedure, SBRT requires only a few visits to the radiation department and may be of interest for the elderly or, in the case of primary RCC, for patients who are not considered surgical candidates due to technical limitations, medical comorbidities, or in the event that the maintenance of kidney function is compromised. In the treatment landscape of oligometastatic RCC, SBRT shows promise in eradicating metastatic disease and delaying the initiation of systemic treatment. Technical advancements in the planning and administration of radiation treatment and improvements in movement management allow irradiating the tumor and/or metastatic lesions with very high doses in few fractions while maximally sparing the surrounding organs at risk, thus minimizing toxicity. In that context, the increasing availability of particle therapy, such as proton beam radiotherapy or carbon ion radiotherapy, could further optimize the delivery of radiation treatment in order to reduce toxicity and improve outcome.
\end{abstract}


Keywords: Particle therapy, proton therapy, carbon ion radiation therapy

\section{INTRODUCTION}

Renal cell carcinoma (RCC) accounts for $3 \%$ of all cancers worldwide and is the most common solid tumor within the kidney representing approximately $90 \%$ of all kidney malignancies ${ }^{[1]}$. There are different RCC subtypes, of which clear cell carcinoma is the most common histopathology. The majority of the lesions is diagnosed as small tumors, with a notable proportion of locally advanced disease and up to $20 \%$ of patients presenting with distant metastases at the time of diagnosis ${ }^{[1]}$. For non-metastatic renal cell carcinoma (nmRCC), surgery including partial and radical nephrectomy are considered standard of care, with radiofrequency ablation and cryoablation as alternative treatment options for selected patients with small renal masses ${ }^{[2]}$. About $20 \%-40 \%$ of non-metastatic patients will eventually develop metastases, for which the standard management consists of immune checkpoint inhibitors (ICI) and/or targeted therapy ${ }^{[2,3]}$. The role of conventional radiotherapy (RT) in palliation of symptoms of metastatic disease is well established.

Stereotactic body radiotherapy (SBRT), targeting oligometastatic disease as well as treating the primary tumor, both with the aim to cure, has more recently become part of the therapeutic armamentarium ${ }^{[3]}$. Due to the advancements in treatment planning and delivery techniques, and the increasing availability of particle therapy using protons or heavy ions such as carbon ions, the interest for SBRT in the field of RCC has grown substantially. In this review, we summarize the current evidence of (SB)RT as a treatment option for $(\mathrm{m}) \mathrm{RCC}$, with a focus on the advantages of particle therapy.

\section{RADIOTHERAPY IN THE TREATMENT OF RCC Working mechanism}

Unlike healthy kidney cells, which are very sensitive to radiation, RCC has traditionally been considered radio-resistant. In addition, surrounding organs at risk such as jejunum, duodenum, and colon are also susceptible to radiation damage. Because of this presumed radio-resistance and the risk of radiationinduced toxicities, RT was considered marginal when it came to treating primary $\mathrm{RCC}^{[4]}$ and/or oligometastatic disease. However, preclinical and clinical evidence has shown that RCC is sensitive to ablative radiation doses (typically $>8$ Gy per fraction), resulting in tumor control rates of approximately $90 \%{ }^{[5]}$. SBRT provides the method to deliver these ablative doses. In contrast to conventionally fractionated RT, which aims to cause DNA-damage, SBRT also induces endothelial damage and tumor cell killing by stimulation of the ceramide pathway ${ }^{[6,7]}$. After irradiation, hydrolyzation of sphingomyelin takes place in the cell membrane, and ceramide is generated, which is a proapoptotic messenger. In addition, SBRT has the ability to activate antitumor host immunity, which can induce the so-called abscopal effect ${ }^{[5,8]}$. First reported in 1953, this phenomenon describes the ability of irradiation to induce tumor regression at non-irradiated, distant tumor sites ${ }^{[9]}$. Although rarely observed historically, the advent of ICI reopened the research interest in this effect. Certainly the combination of SBRT and ICI is an emerging treatment option for mRCC ${ }^{[10,11]}$.

\section{Photon SBRT in primary RCC}

Several recently published reviews extensively describe the role of SBRT in primary RCC $^{[3,5,10]}$. Unfortunately, the number of patients in prospective trials is small, and a comparison with partial or radical nephrectomy, cryotherapy, or radiofrequency ablation (RFA) is lacking. Globally, SBRT is considered a valuable alternative to surgery for elderly patients ( $>70$ years old), patients who are medically inoperable, and patients with pre-existing comorbidities such as arterial hypertension, diabetes mellitus, chronic kidney disease, and/or cardiovascular disease ${ }^{[5]}$. Since cryoablation and RFA both result in less local control (LC) in the case of larger tumors, and central/perihilar location could increase the risk of hemorrhage, fistula 
formation, and ureteral strictures, SBRT is an excellent alternative with LC rates of $97 \%$ for tumors > $4 \mathrm{~cm}^{[12]}$. SBRT might be of particular interest in patients under anticoagulation.

In a total of 26 trials, 382 tumors in 372 patients were treated with SBRT, resulting in a random-effect estimate for LC of $97.0 \%$ (95\%CI: $93.9 \%-99.5 \%)^{[5]}$. LC rates ranged $70 \%-100 \%$ in the eligible studies, with local failures corresponding to an insufficient biological dose (low-dose arm or in the case of compromise to mitigate toxicity). The most prominent toxicity was mild nausea, fatigue, or dermatitis. Grade 3-4 events ranged from $0 \%$ to $25 \%$. The wide range should be interpreted with caution, as the number of patients in the trials was low. Most of the trials report low toxicity, while the $25 \%$ toxicity is the result of a phase 1 doseescalation trial, where $30 \mathrm{~Gy}$ in five fractions resulted in 3 out of 12 patients with Grade 3 fatigue $(n=2)$ and bone pain $(n=1)^{[13]}$. The random effect for the mean estimated glomerular filtration rate (eGFR) difference before and after SBRT was $-7.7 \mathrm{~mL} / \mathrm{min}$ (95\%CI: -12.5 to $-2.8 \mathrm{~mL} / \mathrm{min}$ ), with the eGFR difference ranging from -16.7 to $+6.0^{[5]}$. This is consistent with the eGFR decrease after partial or radical nephrectomy of 13 and $24 \mathrm{~mL} / \mathrm{min}$, respectively, for a median follow-up of 44 and 57 months ${ }^{[14]}$. Overlaying SBRT treatment plans with functional imaging scans $\left({ }^{51} \mathrm{Cr}\right.$-EDTA or ${ }^{99 \mathrm{~m}}$-TC-DSMA SPECT-CT), Siva et al. ${ }^{[15]}$ showed that regional nephropathy and the resulting loss of function occurred clearly in high-dose regions. Fortunately, the contralateral non-irradiated kidney compensated for this loss except in patients with pre-existing nephropathy. Interestingly, there was a clear dose-related decrease in eGFR: for every 10 Gy of physical dose, eGFR decreased by $25 \%-39 \%{ }^{[15]}$. Of note, late onset ( $\geq 1$ year) of eGFR has been described, implicating the need for long-term follow-up and the interest of using functional imaging ${ }^{[5,15]}$. SBRT for primary RCC has thus proven to be effective and well-tolerated, and might even lead to more favorable local control rates when compared to thermal ablative treatments, certainly in case of stage Ib tumors ${ }^{[12]}$.

\section{Photon SBRT in metastatic RCC}

RCC metastases are usually located in the lymph nodes, lung, liver, bone, and brain ${ }^{[3]}$. Up to $20 \%$ of patients have upfront metastatic disease, and about $20 \%-40 \%$ of nmRCC patients will eventually develop metastases $^{[3]}$. Oligometastatic disease, the intermediate state between localized and widespread metastatic disease, typically involves 1-5 metastases. In this particular situation, metastasis-directed therapy (MDT) has evolved as a new treatment option in various tumors, with prostate cancer probably being the most studied urological tumor ${ }^{[16]}$. Both metastasectomy and SBRT are excellent options for performing MDT. Studies reporting on metastasectomy in different organs (lung, bone, brain, liver, etc. ( $^{[17-27]}$ have shown excellent LC and improvement in overall survival (OS) (albeit retrospectively, with an important selection bias), with a five-year survival benefit of $45 \%{ }^{[28]}$. SBRT induces LC rates up to $90 \%-98 \%$ while toxicity rates remain very ${ } \mathrm{low}^{[3,8,29-40]}$. To the best of our knowledge, we are aware of only one (retrospective) trial comparing the two treatment modalities. In general, this trial shows that the results of SBRT are similar to those of metastasectomy ${ }^{[31]}$. Specific to SBRT, there is the theoretical possibility to interfere positively with the immune response elicited by ICI and to decrease the rate of the metastatic spread, as has been shown for other urological malignancies ${ }^{[1,41]}$.

Whether SBRT will improve outcome in oligometastatic RCC patients in combination with ICI or tyrosine kinase inhibitors targeting the vascular endothelial growth factor receptor is the subject of several ongoing $\operatorname{trials}^{[42]}$.

\section{Particle therapy and RCC}

Compared to photons, particle therapy has several advantages, including a favorable dose-depth profile, a higher linear energy transfer (LET), and a higher relative biological effectiveness (RBE) ${ }^{[43]}$, meaning they have the potential to treat "difficult to treat" tumors, in terms of location (deep seated or critically located), radio-resistance, or a highly aggressive nature ${ }^{[43]}$. 


\section{A brief overview of the physics rationale}

Most particle therapy worldwide is performed with protons (PBT) or carbon ions (CIRT). Both modalities have the potential to deliver a very high radiation dose to the tumor with maximum sparing of the surrounding healthy tissues ${ }^{[4]}$. Through the radiation beam entrance path, there is only a low-dose deposition, followed by a rapid incline in energy deposition with most of the energy deposited at the end of the ionization track (i.e., the location of the tumor) and limited or no exit dose $e^{[45]}$. This peak of dose deposition at a specific depth is known as the Bragg peak ${ }^{[43]}$. To adequately cover the target (i.e., tumor lesion), the Bragg peak is spread out to an optimal range, called "spread-out Bragg peak". The characteristic dose deposition at depth for photon, PBT, and CIRT is depicted in Figure 1. An example of a photon treatment plan compared to a proton treatment plan for primary RCC is presented in Figure 2.

Secondly, compared to photons, particle therapy has a higher LET, a quantification of the amount of energy transferred from the ion to the tissue. While photon therapy results in "simple DNA damage", the "complex DNA damage" caused by the particle therapy is a clustering of multiple DNA lesions in close proximity, making DNA repair more difficult ${ }^{[43]}$. A higher LET thus correlates with a higher relative RBE and consequently produces more cell killing at equivalent doses ${ }^{[43]}$. Compared to the RBE of 1 for photon therapy, the RBEs for PBT and CIRT are considered 1.1 and 2.5-3, respectively.

\section{Particle therapy in primary RCC}

The initial results of particle therapy in primary RCC are encouraging ${ }^{[3]}$. The clinical and dosimetric comparative trials that have reported on the use of PBT or CIRT for RCC are listed in Table 1. We briefly describe the trials hereunder.

In one case report, Frick et al. ${ }^{[4]}$, reported on the use of proton SBRT in a 47-year-old women diagnosed with bilateral Grade 1-2 clear cell RCCs. The patient was inoperable due to multiple comorbidities including stage 2 chronic kidney disease (CKD). A total dose of $30 \mathrm{~Gy}$ in five fractions was administered to both lesions. She experienced acute but transient Grade 1 urinary urgency and urinary incontinence, as well as Grade 1 fatigue, which recovered to pre-treatment three months after treatment. Marginal deterioration in renal function was observed (from 34 to $29 \mathrm{~mL} / \mathrm{min} / 1.73 \mathrm{~m}^{2}$ ). The one-year follow-up showed stable tumor findings on the MRI. The authors concluded that proton therapy is feasible and a promising therapeutic approach that can be considered for medically inoperable patients $\mathrm{s}^{[4]}$.

In a multi-institutional retrospective study, Fukumitsu et al. ${ }^{[46]}$ investigated the efficacy of PBT as a treatment for RCC in 22 patients. The majority of these patients had T1a tumors (77\%). The total irradiation dose was 60.0-79.6 Gy (RBE) delivered in 10-36 fractions and the biological equivalent doses ranged from 94 to $110 \mathrm{~Gy}$ (median $105 \mathrm{~Gy}$ ). At a median follow-up of 37 months, the three-year local control, diseasespecific survival, and overall survival rates were $100 \%, 100 \%$, and $95 \%$. One patient developed Grade 2 acute dermatitis, and two patients developed Grade 2 renal dysfunction at 9 and 28 months, respectively. The mean estimated glomerular filtration rate was reduced by $7.1 \pm 11.2 \mathrm{~mL} / \mathrm{min} / 1.73 \mathrm{~m}^{2}$, which is comparable to the above-mentioned renal function decline after photon therapy.

We identified two dosimetric analyses of PBT in kidney cancer ${ }^{[4748]}$. Baydoun et al ${ }^{[47]}$ evaluated the dosimetric characteristics of Cyberknife ${ }^{\ominus}$, Volumetric Modulated Arc Therapy (VMAT), and PBT in the stereotactic treatment of RCC. The prescribed dose was $48 \mathrm{~Gy}$ to be delivered in four fractions. Compared to Cyberknife ${ }^{\oplus}$, both VMAT and PBT provided equivalent or superior coverage of the target volume while reducing treatment time per fraction and consequently also intra-fraction motion. Dose to the remaining target kidney, contralateral kidney, liver, spinal cord, and intestine was limited. 
Table 1. Overview of published trials on particle therapy in RCC

\begin{tabular}{|c|c|c|c|c|c|c|c|c|c|}
\hline Name (Ref.) & Setting & $\begin{array}{l}\text { Study } \\
\text { design }\end{array}$ & $\begin{array}{l}\text { Type of } \\
\text { treatment }\end{array}$ & $n$ & $\begin{array}{l}\text { Dose } \\
\text { (BED) }\end{array}$ & $\begin{array}{l}\text { Med FU } \\
\text { (mo) }\end{array}$ & DSS & OS & Toxicity \\
\hline Fukumitsu et al. ${ }^{[46]}$ & $\begin{array}{l}\text { Primary RCC, } \\
\text { unilateral }\end{array}$ & $\mathrm{R}$ & Proton & 22 & $\begin{array}{l}\text { Range 94- } \\
110 \text { Gy }\end{array}$ & 37 & $\begin{array}{l}100 \% \\
\text { (3-year) }\end{array}$ & $\begin{array}{l}95 \%(3- \\
\text { year })\end{array}$ & $\begin{array}{l}\text { Acute } \geq G 2 \text { in } 5 \% \text { (dermatitis), } \\
\text { late } \geq G 2 \text { in } 9 \% \text { (renal } \\
\text { dysfunction) }\end{array}$ \\
\hline Frick et al. ${ }^{[4]}$ & $\begin{array}{l}\text { Primary RCC, } \\
\text { bilateral }\end{array}$ & $\mathrm{R}$ & Proton & 1 & $48 \mathrm{~Gy}$ & 12 & $\begin{array}{l}100 \% \\
(1-\text { year })\end{array}$ & $\begin{array}{l}100 \% \\
(1-\text { year })\end{array}$ & Acute G1 (GU, fatigue) \\
\hline Nomiya et al. ${ }^{[49]}$ & $\begin{array}{l}\text { Primary RCC, } \\
\text { unilateral }\end{array}$ & $\mathrm{R}$ & CIRT & 10 & $\begin{array}{l}\text { Range 86- } \\
120 \mathrm{~Gy}\end{array}$ & 58 & NR & $\begin{array}{l}74 \%(5- \\
\text { year) }\end{array}$ & Late G4 in 10\% (dermatitis) \\
\hline Kasuya et al. ${ }^{[50]}$ & Primary RCC & $\mathrm{R}$ & CIRT & 19 & 90 Gy & 79 & $\begin{array}{l}100 \% \\
\text { (5-year) }\end{array}$ & $\begin{array}{l}89 \%(5- \\
\text { year) }\end{array}$ & $\begin{array}{l}\mathrm{G} 4 \text { in } 21 \% \text { (CKD) and } \mathrm{G} 4 \text { in } \\
5 \% \text { (dermatitis) }\end{array}$ \\
\hline Kasuya et al. ${ }^{[51]}$ & $\begin{array}{l}\text { Primary RCC, } \\
\text { unilateral }\end{array}$ & $P$ & CIRT & 8 & $\begin{array}{l}\text { Range 93- } \\
104 \text { Gy }\end{array}$ & 43 & $100 \%$ & NR & Acute G1 (skin) \\
\hline Baydoun et al. ${ }^{[47]}$ & $\begin{array}{l}\text { Primary RCC, } \\
\text { unilateral }\end{array}$ & DA & $\begin{array}{l}\text { Photon vs. } \\
\text { proton }\end{array}$ & 10 & $\begin{array}{l}\text { Range 38- } \\
106 \mathrm{~Gy}\end{array}$ & NA & NA & NA & NA \\
\hline Thompson et al. ${ }^{[48]}$ & $\begin{array}{l}\text { Primary RCC, } \\
\text { unilateral }\end{array}$ & DA & $\begin{array}{l}\text { Photon vs. } \\
\text { proton }\end{array}$ & 3 & $151 \mathrm{~Gy}$ & NA & NA & NA & NA \\
\hline
\end{tabular}

N: number; BED: biologically effective dose (for alpha/beta =10 Gy); RCC: renal cell carcinoma; med FU (mo): median follow-up (months); DSS: disease-specific survival; OS: overall survival; R: retrospective study design; P: prospective study design; DA: dosimetric analysis; G: grade; Gy: Gray (unit); GU: genito-urinary; NR: not reported; NA: not applicable; CIRT: carbon ion radiotherapy; CKD: chronic kidney disease.

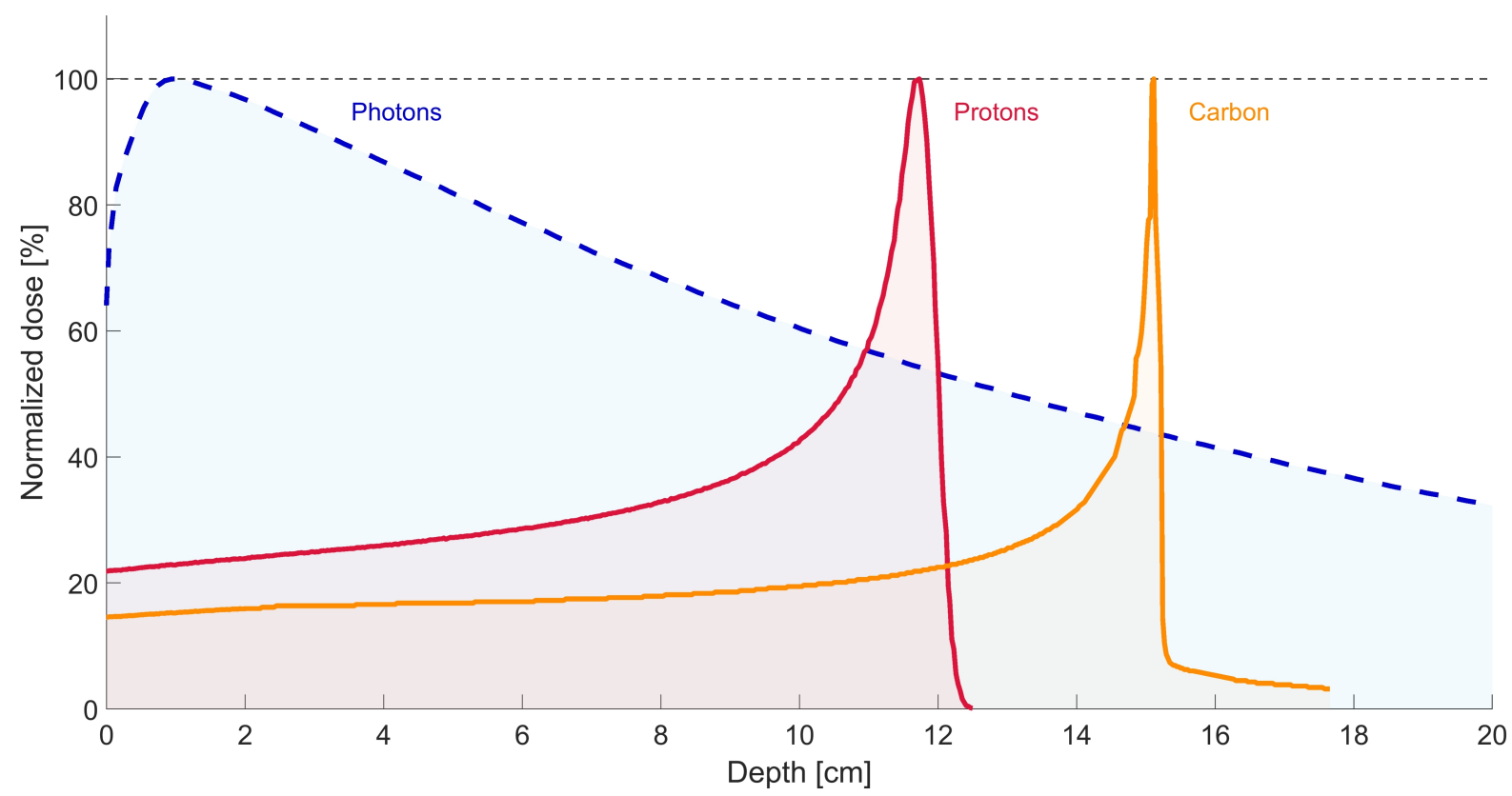

Figure 1. Dose-depth curves of (6 MV FFF) photons (blue dotted line) vs. (130 MeV) proton (red line) vs. (270 MeV) carbon ion (orange line).

Thompson et al. ${ }^{[48]}$ investigated the nephron-sparing potential of proton SBRT for early stage RCC. In three randomly selected (non-RCC) patients previously treated for pancreatic cancer, they drew spherical contours to mimic renal tumors at four locations in the kidney, for which VMAT plans and PBT plans were generated. The dose prescription was $54 \mathrm{~Gy}$ in three fractions. The volume of the kidney receiving $12 \mathrm{~Gy}$ (V12 Gy) showed an average improvement of $13 \%$ in the case of single-beam PBT. In addition, dose to the duodenum and small bowel was significantly lower, with a mean V20 Gy of 0.39 and $2.31 \mathrm{cc}$, respectively, for proton plans, compared to 1.54 and $5.54 \mathrm{cc}$, respectively, for photon plans. 

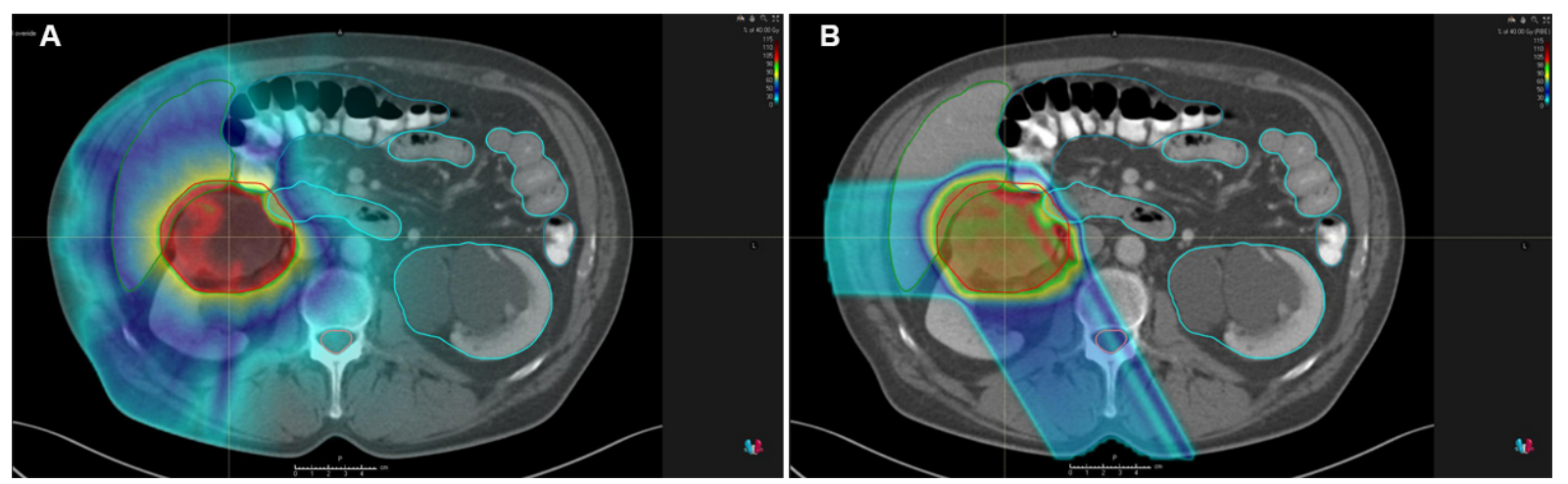

Figure 2. An example of a photon treatment plan (A) vs. proton treatment plan (B) of a primary RCC in the upper pole of the right kidney.

There are two retrospective trials reporting on CIRT in primary RCC. Nomiya et al.$^{[4]]}$ reported on 10 patients treated with CIRT for unilateral RCC. The prescribed dose was 72 GyE in 16 fractions. After a median follow-up of 58 months, the five-year LC rate, progression-free survival, DSS, and OS were 100\%, $100 \%, 100 \%$, and $74 \%$, respectively. No acute toxicity above Grade 1 was observed. One patient developed a skin ulcer five years after treatment, which was treated with a skin flap transplantation giving rise to this Grade 4 toxicity. In two patients with diabetic nephropathy, renal function deteriorated significantly after CIRT, but this was not the case in the other patients.

Kasuya et al..$^{[50]}$ updated the results of 19 CIRT treated patients. Fifteen patients were treated with a 16fraction scheme, of whom 10 patients received a total dose of $72 \mathrm{~Gy}$ (RBE) in 16 fractions. A dose-escalation to $80 \mathrm{~Gy}$ was performed in three patients. A total dose of $64 \mathrm{~Gy}$ in 16 fractions, used in case of anatomical proximity to the gastrointestinal tract, was given in the other two patients. Four patients received a prescribed fractionation schedule of 66 Gy (RBE) in 12 fractions. For a median follow-up of 6.6 years, the LC rates, DFS, DSS, and OS rates were $94 \%, 69 \%, 100 \%$, and $89 \%$, respectively. Seven patients presented with Grade 2 CKD, of whom four progressed to Grade 4 CKD. Notably, all four patients who deteriorated to Grade 4 CKD had definitive renal comorbidities pre-CIRT, such as diabetic nephropathy, renal sclerosis, or a solitary kidney. While caution is advised in patients with pre-existing renal comorbidities, the authors noted that progression to Grade 4 took an average of 5.6 years, so the natural course of renal disease cannot be ruled out. One patient had Grade 4 dermatitis, and one patient had a subcutaneous induration requiring painkillers. Both patients had undergone dose escalation to $80 \mathrm{~Gy}$ in 16 fractions.

Kasuya et al..$^{[51]}$ also reported the results of a prospective clinical trial, in which eight patients were treated with CIRT for unilateral RCC. Five patients received 66 Gy in 16 fractions. Since no dose-limiting toxicity occurred, the following three patients were treated up to $72 \mathrm{~Gy}$ in 16 fractions. For a median follow-up of 43 months, the LC and DSS were $100 \%$. No patient developed Grade 3 or higher acute or late toxicity. The average decrease in eGFR at the end of follow-up was $10.8 \mathrm{~mL} / \mathrm{min} / 1.73 \mathrm{~m}^{2}$.

For follow-up purposes, it should be noted that there was no volume change or even a transient enlargement during observation in the months following treatment with particle therapy. At long-term follow-up, a very gradually shrinkage pattern was observed ${ }^{[4,46,49]}$. Therefore, follow-up imaging after CIRT should be used with caution so as not to misinterpret local failure. 


\section{PBT and CIRT for metastatic RCC}

Nakao et al..$^{[52]}$ (abstract only) reported a case of a 70-year-old woman treated with CIRT for lung and lymph node metastases five years after previous radical nephrectomy. They observed 100\% LC in the irradiated lesions at the time of last follow-up. We could not find any other studies with PBT/CIRT for RCC. Planning studies have shown that SBRT plans for spinal metastases for proton and carbon ion RT were feasible ${ }^{[53,54]}$. For equivalent tumoral coverage, the maximum spinal cord dose was lower for PBT/CIRT, and the treatment time was shorter ${ }^{[53]}$. Future prospective trials will need to elaborate the real benefit of PBT and/or CIRT for metastatic RCC.

\section{Challenges and future prospects}

Organ movements (e.g., by breathing) and variability in setup (positioning of the patient) can cause uncertainties in administrating the correct dose. Knowing that motion management is already a challenge in photon SBRT for primary RCC and metastatic lesions subject to motion, this is even more so for particle therapy ${ }^{[55,56]}$ due to density changes along the beam path that may cause the Bragg peak to occur at a different location than planned, and the interplay between organ motion (especially breathing motion) and beam delivery technique ${ }^{[57]}$. Range uncertainty, due to patient positioning and movement, is seen as a limiting factor. Robust optimization for treatment planning, four-dimensional planning CT (coping with breathing), and image-guided RT are essential parts of the treatment, to mitigate the potentially deteriorating impact of range uncertainty and inter- and intrafraction motion on the dose distribution ${ }^{[55,58]}$.

Although many other trials are underway regarding SBRT for primary or (oligo)metastatic RCC with photon beam radiotherapy, we are not aware of any ongoing trials with PBT or CIRT for these indications. Prospective trials are badly needed. However, this type of research is limited due to the availability of particle therapy, as well as the higher treatment costs that require appropriate patient selection to ensure a cost-effective implementation of the techniques in daily practice ${ }^{[59]}$.

\section{CONCLUSION}

Encouraging results are seen with both photon and particle (SB)RT for the treatment of primary RCC, but prospective trials are needed with a longer follow-up and sufficient patient numbers. PBT and/or CIRT may also be important for the treatment of metastatic lesions adjacent to critical organs. CIRT in particular shows promising results because of its advantages in dose distribution and biological effect.

\section{DECLARATIONS}

\section{Acknowledgments}

Charlien Berghen is a PhD student at KU Leuven, receiving a grant from "Kom op tegen kanker" (Stand up to Cancer). Kato Rans is a PhD student at KU Leuven, receiving a grant from "Stichting tegen Kanker". Steven Joniau is a senior clinical researcher of the FWO (research foundation flanders). No writing assistance was utilized in the production of this manuscript.

\section{Authors' contribution}

Literature search, content of the manuscript, data collection, data interpretation, writing of the manuscript: Berghen C

Critical review of the manuscript, advice on surgical items: Albersen $\mathrm{M}$

Creation of figure 1 and 2, critical review of the manuscript, advice on technical parts of radiation therapy: De Roover R

Critical review of the manuscript: Rans K 
Critical review of the manuscript, advice on medical oncology: Beuselinck B

Critical review of the manuscript, advice on surgical items: Decaestecker K

Creation figure 1, critical review of the manuscript, advice on technical parts of radiation therapy: Poels K

Critical review of the manuscript: Otte F

Critical review of the manuscript, advice on surgical items: Joniau $S$

Critical review of the manuscript, advice on proton beam therapy: Haustermans $\mathrm{K}$

Content of the manuscript, data interpretation, writing of the manuscript: De Meerleer G

\section{Availability of data and materials}

Not applicable.

\section{Financial support and sponsorship}

None.

\section{Conflicts of interest}

All authors declared that there are no conflicts of interest.

\section{Ethics approval and consent to participate}

Not applicable.

\section{Consent for publication}

Not applicable.

\section{Copyright}

(c) The Author(s) 2021.

\section{REFERENCES}

1. Capitanio U, Bensalah K, Bex A, et al. Epidemiology of renal cell carcinoma. Eur Urol 2019;75:74-84. DOI PubMed PMC

2. Ljungberg B, Albiges L, Bedke J. EAU guidelines on renal cell carcinoma. Available from: https:/uroweb.org/guideline/renal-cellcarcinoma/ [Last accessed on 14 Sep 2021].

3. Rühle A, Andratschke N, Siva S, Guckenberger M. Is there a role for stereotactic radiotherapy in the treatment of renal cell carcinoma? Clin Transl Radiat Oncol 2019;18:104-12. DOI PubMed PMC

4. Frick MA, Chhabra AM, Lin L, Simone CB 2nd. First ever use of proton stereotactic body radiation therapy delivered with curative intent to bilateral synchronous primary renal cell carcinomas. Cureus 2017;9:e1799. DOI PubMed PMC

5. Correa RJ, Louie AV, Zaorsky NG, et al. The emerging role of stereotactic ablative radiotherapy for primary renal cell carcinoma: a systematic review and meta-analysis. Eur Urol Focus 2019;5:958-69. DOI PubMed

6. De Meerleer G, Khoo V, Escudier B, et al. Radiotherapy for renal-cell carcinoma. Lancet Oncol 2014;15:e170-7. DOI PubMed

7. Sathishkumar S, Boyanovsky B, Karakashian AA, et al. Elevated sphingomyelinase activity and ceramide concentration in serum of patients undergoing high dose spatially fractionated radiation treatment: implications for endothelial apoptosis. Cancer Biol Ther 2005;4:979-86. DOI PubMed

8. Siva S, Kothari G, Muacevic A, et al. Radiotherapy for renal cell carcinoma: renaissance of an overlooked approach. Nat Rev Urol 2017;14:549-63. DOI PubMed

9. Reynders K, Illidge T, Siva S, Chang JY, De Ruysscher D. The abscopal effect of local radiotherapy: using immunotherapy to make a rare event clinically relevant. Cancer Treat Rev 2015;41:503-10. DOI PubMed PMC

10. Tselis N, Chatzikonstantinou G. Treating the Chameleon: radiotherapy in the management of Renal Cell Cancer. Clin Transl Radiat Oncol 2019;16:7-14. DOI PubMed PMC

11. Ingrosso G, Becherini C, Francolini G, et al. Stereotactic body radiotherapy (SBRT) in combination with drugs in metastatic kidney cancer: A systematic review. Crit Rev Oncol Hematol 2021;159:103242. DOI PubMed

12. Siva S, Correa RJM, Warner A, et al. Stereotactic ablative radiotherapy for $\geq \mathrm{T} 1 \mathrm{~b}$ primary renal cell carcinoma: a report from the international radiosurgery oncology consortium for kidney (IROCK). Int J Radiat Oncol Biol Phys 2020;108:941-9. DOI PubMed

13. Correa RJM, Ahmad B, Warner A, et al. A prospective phase I dose-escalation trial of stereotactic ablative radiotherapy (SABR) as an alternative to cytoreductive nephrectomy for inoperable patients with metastatic renal cell carcinoma. Radiat Oncol 2018;13:47. DOI PubMed PMC

14. Simmons MN, Weight CJ, Gill IS. Laparoscopic radical versus partial nephrectomy for tumors $>4 \mathrm{~cm}$ : intermediate-term oncologic and functional outcomes. Urology 2009;73:1077-82. DOI PubMed 
15. Siva S, Jackson P, Kron T, et al. Impact of stereotactic radiotherapy on kidney function in primary renal cell carcinoma: establishing a dose-response relationship. Radiother Oncol 2016;118:540-6. DOI PubMed

16. Devos G, Berghen C, Van Eecke H, et al. Oncological outcomes of metastasis-directed therapy in oligorecurrent prostate cancer patients following radical prostatectomy. Cancers (Basel) 2020;12:2271. DOI PubMed PMC

17. Alt AL, Boorjian SA, Lohse CM, Costello BA, Leibovich BC, Blute ML. Survival after complete surgical resection of multiple metastases from renal cell carcinoma. Cancer 2011;117:2873-82. DOI PubMed

18. Yang JC, Abad J, Sherry R. Treatment of oligometastases after successful immunotherapy. Semin Radiat Oncol 2006;16:131-5. DOI PubMed

19. Tanis PJ, van der Gaag NA, Busch OR, van Gulik TM, Gouma DJ. Systematic review of pancreatic surgery for metastatic renal cell carcinoma. Br J Surg 2009;96:579-92. DOI PubMed

20. Karam JA, Rini BI, Varella L, et al. Metastasectomy after targeted therapy in patients with advanced renal cell carcinoma. J Urol 2011;185:439-44. DOI PubMed PMC

21. Russo AE, Untch BR, Kris MG, et al. Adrenal metastasectomy in the presence and absence of extraadrenal metastatic disease. Ann Surg 2019;270:373-7. DOI PubMed PMC

22. Kollender Y, Bickels J, Price WM, et al. Metastatic renal cell carcinoma of bone: Indications and technique of surgical intervention. $J$ Urol 2000;164:1505-8. PubMed

23. Lin PP, Mirza AN, Lewis VO, et al. Patient survival after surgery for osseous metastases from renal cell carcinoma. J Bone Joint Surg Am 2007;89:1794-801. DOI PubMed

24. Higuchi T, Yamamoto N, Hayashi K, et al. Long-term patient survival after the surgical treatment of bone and soft-tissue metastases from renal cell carcinoma. Bone Joint J 2018;100-B:1241-8. DOI PubMed

25. Vickers MM, Al-Harbi H, Choueiri TK, et al. Prognostic factors of survival for patients with metastatic renal cell carcinoma with brain metastases treated with targeted therapy: results from the international metastatic renal cell carcinoma database consortium. Clin Genitourin Cancer 2013;11:311-5. DOI PubMed

26. Stief C, Hagemann J, Kuczyk M, Jonas U. Surgery for metachronous solitary liver metastases of renal cell carcinoma. J Urol 1997;158:375-7. PubMed

27. Alves A, Adam R, Majno P, et al. Hepatic resection for metastatic renal tumors: is it worthwhile? Ann Surg Oncol 2003;10:705-10. DOI PubMed

28. Loh J, Davis ID, Martin JM, Siva S. Extracranial oligometastatic renal cell carcinoma: current management and future directions. Future Oncol 2014;10:761-74. DOI PubMed

29. Franzese C, Franceschini D, Di Brina L, et al. Role of stereotactic body radiation therapy for the management of oligometastatic renal cell carcinoma. J Urol 2019;201:70-6. DOI PubMed

30. Cochran DC, Chan MD, Aklilu M, et al. The effect of targeted agents on outcomes in patients with brain metastases from renal cell carcinoma treated with Gamma Knife surgery. J Neurosurg 2012;116:978-83. DOI PubMed PMC

31. Stenman M, Sinclair G, Paavola P, Wersäll P, Harmenberg U, Lindskog M. Overall survival after stereotactic radiotherapy or surgical metastasectomy in oligometastatic renal cell carcinoma patients treated at two Swedish centres 2005-2014. Radiother Oncol 2018;127:501-6. DOI PubMed

32. Svedman C, Sandström P, Pisa P, et al. A prospective Phase II trial of using extracranial stereotactic radiotherapy in primary and metastatic renal cell carcinoma. Acta Oncol 2006;45:870-5. DOI PubMed

33. Meyer E, Pasquier D, Bernadou G, et al. Stereotactic radiation therapy in the strategy of treatment of metastatic renal cell carcinoma: a study of the Getug group. Eur J Cancer 2018;98:38-47. DOI PubMed

34. Marvaso G, Corrao G, Oneta O, et al. Oligo metastatic renal cell carcinoma: stereotactic body radiation therapy, if, when and how? Clin Transl Oncol 2021;23:1717-26. DOI PubMed

35. Kano H, Iyer A, Kondziolka D, Niranjan A, Flickinger JC, Lunsford LD. Outcome predictors of gamma knife radiosurgery for renal cell carcinoma metastases. Neurosurgery 2011;69:1232-9. DOI PubMed

36. Singh R, Ansinelli H, Sharma D, et al. Stereotactic body radiation therapy (SBRT) for metastatic renal cell carcinoma: a multiinstitutional experience. J Radiosurg SBRT 2020;7:29-37. PubMed PMC

37. Ranck MC, Golden DW, Corbin KS, et al. Stereotactic body radiotherapy for the treatment of oligometastatic renal cell carcinoma. Am J Clin Oncol 2013;36:589-95. DOI PubMed

38. Wersäll PJ, Blomgren H, Lax I, et al. Extracranial stereotactic radiotherapy for primary and metastatic renal cell carcinoma. Radiother Oncol 2005;77:88-95. DOI PubMed

39. Zelefsky MJ, Greco C, Motzer R, et al. Tumor control outcomes after hypofractionated and single-dose stereotactic image-guided intensity-modulated radiotherapy for extracranial metastases from renal cell carcinoma. Int J Radiat Oncol Biol Phys 2012;82:1744-8. DOI PubMed PMC

40. Ikushima H, Tokuuye K, Sumi M, et al. Fractionated stereotactic radiotherapy of brain metastases from renal cell carcinoma. Int $J$ Radiat Oncol Biol Phys 2000;48:1389-93. DOI PubMed

41. Gundem G, Van Loo P, Kremeyer B, et al; ICGC Prostate Group. The evolutionary history of lethal metastatic prostate cancer. Nature 2015;520:353-7. DOI PubMed PMC

42. Berghen C, Joniau S, Vulsteke C, et al. Metastasis-directed therapy for oligometastatic urological tumours: still no second-hand news. Ecancermedicalscience 2020;14:1036. DOI PubMed PMC

43. Mohamad O, Sishc BJ, Saha J, et al. Carbon ion radiotherapy: a review of clinical experiences and preclinical research, with an emphasis on DNA damage/repair. Cancers (Basel) 2017;9:66. DOI PubMed PMC 
44. Malouff TD, Mahajan A, Krishnan S, Beltran C, Seneviratne DS, Trifiletti DM. Carbon Ion Therapy: a modern review of an emerging technology. Front Oncol 2020;10:82. DOI PubMed PMC

45. Gergelis KR, Jethwa KR, Tryggestad EJ, Ashman JB, Haddock MG, Hallemeier CL. Proton beam radiotherapy for esophagus cancer: state of the art. $J$ Thorac Dis 2020;12:7002-10. DOI PubMed PMC

46. Fukumitsu N, Ishikawa H, Arimura T, et al. Proton therapy for primary renal cell carcinoma: the first nationwide retrospective study in Japan. In Vivo 2020;34:2883-9. DOI PubMed PMC

47. Baydoun A, Vapiwala N, Ponsky LE, et al. Comparative analysis for renal stereotactic body radiotherapy using Cyberknife, VMAT and proton therapy based treatment planning. J Appl Clin Med Phys 2018;19:125-30. DOI PubMed PMC

48. Thompson A, Ding X, Abbott V, et al. Proton stereotactic body radiotherapy as a nephron-sparing approach for patients with localized renal cell carcinoma: a dosimetric analysis. Int J Radiat Oncol 2019;105:E713. DOI

49. Nomiya T, Tsuji H, Hirasawa N, et al. Carbon ion radiation therapy for primary renal cell carcinoma: initial clinical experience. Int $J$ Radiat Oncol Biol Phys 2008;72:828-33. DOI PubMed

50. Kasuya G, Tsuji H, Nomiya T, et al; Working Group for Genitourinary Tumors. Updated long-term outcomes after carbon-ion radiotherapy for primary renal cell carcinoma. Cancer Sci 2018;109:2873-80. DOI PubMed PMC

51. Kasuya G, Tsuji H, Nomiya T, et al; Working Group for Genitourinary Tumors. Prospective clinical trial of 12-fraction carbon-ion radiotherapy for primary renal cell carcinoma. Oncotarget 2019;10:76-81. DOI PubMed PMC

52. Nakao HT. A case of lung and lymphnode metastasis treated with carbon ion radiotherapy after radical nephrectomy for renal cell carcinoma. Hinyokika Kiyo 2008;54:345-7. DOI

53. Rief H, Chaudhri N, Tonndorf-Martini E, et al. Intensity-modulated radiotherapy versus proton radiotherapy versus carbon ion radiotherapy for spinal bone metastases: a treatment planning study. J Appl Clin Med Phys 2015;16:186-194. DOI PubMed PMC

54. Macewan I, Chou B, Mifflin R, Wroe A, Bush D. Passively scattered proton stereotactic body radiation therapy for spine metastasis: a dosimetric analysis. Int J Radiat Oncol 2016;96:E675-6. DOI

55. Loeffler JS, Durante M. Charged particle therapy-optimization, challenges and future directions. Nat Rev Clin Oncol 2013;10:411-24. DOI PubMed

56. Ruysscher D, Sterpin E, Haustermans K, Depuydt T. Tumour movement in proton therapy: solutions and remaining questions: a review. Cancers (Basel) 2015;7:1143-53. DOI PubMed PMC

57. Bert C, Durante M. Motion in radiotherapy: particle therapy. Phys Med Biol 2011;56:R113-44. DOI

58. Buti G, Souris K, Montero AMB, Lee JA, Sterpin E. Towards fast and robust 4D optimization for moving tumors with scanned proton therapy. Med Phys 2019;46:5434-43. DOI PubMed

59. Verma V, Mishra MV, Mehta MP. A systematic review of the cost and cost-effectiveness studies of proton radiotherapy. Cancer 2016;122:1483-501. DOI PubMed 